\title{
Physical activity in elderly Kidney Transplant patients with Multiple Renal Arteries
}

Armando Calogero ${ }^{1,2, \dagger}$, Caterina Sagnelli ${ }^{3, \dagger}$, Gaia Peluso ${ }^{1, \dagger}$, Antonello Sica ${ }^{4, \dagger}$, Maria Candida ${ }^{1, \dagger}$,

Silvia Campanile ${ }^{1}$, Gianluca Minieri ${ }^{1}$, Paola Incollingo ${ }^{1}$, Massimiliano Creta $^{2}$, Luigi Pelosio ${ }^{1}$,

Vincenzo Tammaro ${ }^{1}$, Alessandro Scotti ${ }^{1}$, Akbar Jamshidi ${ }^{1}$, Marcello Caggiano ${ }^{1}$, Evangelista Sagnelli ${ }^{4}$, Concetta Anna Dodaro ${ }^{1,3}$, Nicola Carlomagno $^{1}$, Michele Santangelo ${ }^{1,2}$

1 General Surgery and Transplant Unit, Department of Advanced Biomedical Sciences, University of Naples Federico II, Naples, Italy.

2 Department of Nephrology, Urology, General Surgery and Kidney Transplants, Anesthesiology and Intensive Care, University Federico II, Naples, Italy

3. Department of Mental Health and Public Medicine, University of Campania Luigi Vanvitelli, Naples, Italy.

4 Department of Precision Medicine, University of Campania Luigi Vanvitelli, Naples, Italy. †equally contributed to this work.

Corresponder to: Prof.ssa Caterina Sagnelli, Department of Mental Health and Public Medicine, University of Campania Luigi Vanvitelli, Naples, Italy, Italy, 80131, Tel: +393938107860, fax: +390815666477, 80131, e-mail: sagnelli.caterina@libero.it

Conflict-of-interest statement: All the authors of the manuscript declare they have no conflict of interest in connection with this paper.

Competing Interests: The authors have declared that no competing interests exist. 


\section{ABSTRACT}

Kidney transplantation is the treatment of choice for patients with end-stage disease. To expand the donor reserve, it is necessary to use marginal/sub optimal donors that provide marginal organs. We retrospectively evaluated the short and long-term outcome of elderly kidney transplantation using allografts with vascular abnormalities. Between January 1999 and December 2018, 740 transplants from cadaveric donors were performed. Thirty-four elderly patients received a kidney transplantation with vascular anatomical variants (Group 1) were compared with 34 patients who received a kidney transplantation with single renal artery (SRA) (Grroup2) pair-matched by age, dialysis age, donor age, comorbidity.

All participants completed the Long Form International Physical Activity Questionnaire (IPAQ) at baseline and after 4, 8, and 12 weeks after transplantation. The overall rate of surgical complications was $17.6 \%$ in Group 1 and $20.6 \%$ in Group 2, indicating that kidney with vascular anatomical variant might be successfully transplanted.

Our data also emphasizes the importance of individualized physical activity in kidney transplantation with multiple arteries. Physical activity should be considered as an essential part of the medical care for renal-transplanted recipients.

Key words: Physical activity, Kidney Transplantation, Elder Age, Vascular Anomalies, Marginal Kidneys 


\section{INTRODUCTION}

Renal transplantation is the treatment of choice for patients with end-stage renal disease [1-7]. Kidneys for transplant come from a living donor or a deceased (cadaver) donor; in Italy, more frequently in the south of country, cadaveric donors are still the major organs source [8-11]. To expand the donors' pool, it is also necessary to use marginal donors who provide marginal organs. Given the donor scarceness the possibility to transplant a kidney with vascular anomalies, i.e. suboptimal kidneys, should considered [12-17].

A kidney is considered suboptimal when, it presents complex arterial anomalies (more than 2 arteries, with single patch or separated patches requiring a double anastomosis or a bench reconstruction), or parenchymal damage (focal sclerosis areas or sutured polar branches accidentally damaged during the organ harvesting, or kidneys with complex anomalies of the excretory tract) that can lead to a reduced nephron mass but not its quality [18-21].

In the past, the kidneys with anatomic anomalies were not considered for transplantation, but now, due to the increasing demand for transplantable kidneys, the criteria for renal transplantation [22-24] were expanded so to include also suboptimal kidneys [25-30].

Renal anatomic anomalies are frequently observed during kidney transplantation, the most common being multiple renal arteries (18-43\% of cases) [31,32] which does not exclude the possibility of using such kidneys for transplantation.

Physical activity is recommended for kidney transplant recipients as it may improve exercise capacity, muscle strength, and health-related quality of life. [33-36]

In this study, we analyze the short- and long-term outcomes of kidney transplantation using allografts with vascular anomalies in 34 kidney-transplanted patients between January 1999 and December 2018 at our center. The effect of physical activity during the follow-up was also evaluated.

\section{PATIENTS AND METHODS}


Between January 1999 and December 2018, 740 transplants from cadaveric donors were performed at the Department of Nephrology, Urology, General Surgery and Kidney Transplants, Anesthesiology and Intensive Care, University Federico II, Naples. Between these 740, we selected 34 kidneys with vascular anatomical variants, i.e. sub-optimal kidneys (Group 1). The 34 patients who received these 34 kidneys were compared with 34 single renal artery (SRA) recipient (Group 2), chosen for homogeneity of characteristics (pair-matched by age, dialysis age, donor age, comorbidity).

We retrospectively compared the incidence of surgical complications, post-transplant hypertension, mean creatinine clearances and graft survivals between patients in these two groups.

\subsection{Physical activity}

All patients completed the Long Form International Physical Activity Questionnaire (IPAQ) at baseline (kidney transplant) and after 4, 8, and 12 weeks after transplantation. Physical activity and sitting times were measured using the long form, past 7-day, self-administered IPAQ [37]. The most common methods used to evaluate physical activity are based on self-reported questionnaires, which are easy to use and inexpensive. Indeed, it has been reported that using the International Physical Activity Questionnaire (IPAQ), that is one of the most complete and commonly used, the relationship between physical activity and some diseases risk factors is hidden. The IPAQ used in our study contained 27 questions concerning physical activity, accompanied by 4 questions providing demographic data such as sex, age, educational level, and type of professional activity. Five activity domain areas were considered: job-related physical activity; transportation physical activity; housework, house maintenance, and caring for family; recreation, sport, leisure-time physical activity; and time spent sitting. The IPAQ assesses frequency (days), duration (minutes), and intensity (light, moderate, vigorous) of physical activity. Moderate physical activity was defined as "those activities that take moderate physical effort and make you breathe somewhat harder than usual"; vigorous physical activity was defined as "those activities that take hard physical effort and make you breathe much harder than normal.” [38]. 
For each patient, the program of physical activity was adjusted to the patient's baseline level of physical activity and consisted of a choice of endurance training involving walking or cycling. The management of our patient required a monthly physician evaluation for at least 12 months after kidney transplantation. Subjects performed the exercises 5 days per week. From the third week on, the exercises were performed individually at home. During the first week, each exercise session lasted 20 minutes and, then it was gradually increased to 2 hours in the fourth week.

Weekly exercise included 5x10 minutes of cycling on a stationary bike at a moderate intensity and $3 \times 10$ minutes of resistance exercise. Resistance training involved six exercises (chest press, uprightseated row, triceps extension, biceps curl, chest fly, and shoulder extension) performed using three set of 3-5 repetitions for each exercise.

Before the start of the exercise training, each patient underwent a check-up consisting of physical examination, electrocardiography, and a baseline assessment of body mass index, general nutritional condition, anthropometry, body composition, and measurement of biochemical parameters.

\section{RESULTS}

Due to the shortage of donors, the use of suboptimal kidneys is increasing in our Transplant Unit. We compared 34 patients in Group 1 who received a kidney with multiple renal arteries (MRA) (Figure 1) with those in Group 2 who received a kidney with a single renal artery (SRA). In Group 1, the recipients' age ranged from 55 to 63 years and the donors' age from 43 to 56 years; in Group 2, the recipients' ranged from 55 years to 58 years and the donor age was from 41 to 55 years (Table 1). Among our deceased donors in Group 2, the causes of death were cerebrovascular accidents in 30 and traumatic injury in the remaining four; whereas in Group 1, 28 donors died for cerebrovascular accidents and six traumatic injuries.

We compared the incidence of post-transplant arterial hypertension and mean creatinine levels after 1, 3 and 5 years of follow-up [39-41]. The mean systolic blood pressure at 1 year was higher among 
patients in Group 1, but over time (1 years versus 5 years), the mean arterial hypertension decreased slightly in both Groups. (Table 1)

Creatinine levels at 1 year ranged from $0.8 \mathrm{mg} / \mathrm{dl}$ to $2.5 \mathrm{mg} / \mathrm{dl}$ in patients the group 2 and from $0.6 \mathrm{mg} / \mathrm{dl}$ to $2.2 \mathrm{mg} / \mathrm{dl}$ in those the Group 1; over time (1-year vs 3 years). There were a decrease in mean creatinine levels in both Groups. (Table 1)

The overall surgical complications rates in Group 2 and 1 were $20.6 \%$ and $17.6 \%$ respectively, a difference not significant to statistical analysis. There was no case of vascular complication in Group 2 while in Group 1 one patient developed thrombosis of renal artery without loss of the graft and with a partial loss of healthy parenchyma. Urologic complications recurred in $2.9 \%$ of cases in Group 1 and in $8.9 \%$ in Group 2. There were 4 cases of symptomatic lymphoceles in both Groups. (Table 2) Patients with complication after surgery were not evaluated for physical activity (7 cases in Group 1 and 8 in Group 2).

In the first two months after kidney transplantation patients in both groups increased the homebased activity to 10 minutes aerobic exercises 4 times a day. Beginning from the $3^{\text {rd }}$ months the exercises program favored the hobbies of the patients including gardening activity for about 10-20 minutes and walking in a row for at least 20 minutes daily and a physical activity of at least 20 minutes consisting in a fast ride in the open air three times a week and in a moderate physical activity in the remaining two days (30-35 consecutive minutes of cycling at a regular pace and carrying light weights).

Most of the patients reported an increases physical activity after transplantation, as compared with the pre-transplant period, but 9\% of patients reported less activity (5\% in Group 1 and 7\% in Group 2); no change in physical activity was observed in 5\% of patients in Group 1 and in $6 \%$ of patients in Group 2.

During the follow-up period a moderate physical activity was reported by the patients in both groups, considering of 3 or more days of vigorous intensity of at least 20 minutes a day, or walking of at least $30 \mathrm{~min} /$ day, and of 3 or more days of any combination of walking, or moderate intensity activity, achieving a minimum of at least $500 \mathrm{MET}-\mathrm{min} /$ week. 


\section{Discussion}

Renal transplantation is the treatment of choice for patients with end-stage renal disease. For many years, transplants with MRA have represented a relative contraindication because of the increased risk of vascular and urologic complications, possibly leading to allograft loss [42-46].

In our series, we found no difference in short- and long-term kidney graft outcomes based on the number of renal arteries and the technique used for anastomosis [47-50]. The presence of aortic patch does not have an impact on graft outcome or on the rate of complications. The incidence of renal graft vascular thrombosis, a serious complication which usually lead to graft loss if untreated, have remained stable during the last three decades, ranging from $0.3 \%$ to $6.1 \%$ [51].

Lack of physical inactivity is a major risk factor for mortality in the general population. A weekly program of physical exercise of 3-5 hours improves the cardiorespiratory fitness, decrease the risk of cardiovascular disease and improve quality of life in the kidney transplant setting [52-55]. It has been shown that level of physical activity may independently predict mortality in chronic kidney diseases [56]. In addition, an increase physical activity as compared with the pretransplant period is correlated with the correction of uremic toxicity.

The beneficial effects of physical activity on physical outcomes and quality of life should induce changes in lifestyle directed toward regular physical activity, as it has been reported in kidney transplantation patients and hemodialysis patients [57-59]. Mazzoni et al. observed that regular physical activity improves health-related quality of life in kidney transplant patient. [60]

Our experience has showed that the presence of kidney vascular anomalies should not be considered a limit for kidney's transplantation. Therefore, kidneys with multiple renal arteries could be transplanted using the technique that best fits in each surgical situation according to the opinion of surgeons [61].

We consider that the success obtained with suboptimal kidney transplantation and with the associated physical activity allowed to extend the utilization of suboptimal kidneys. 


\section{Legend to the figure}

Figure 1. Multiple renal transplant arteries: renal transplant offering three arteries on one patch. 


\section{REFERENCES}

1. De Rosa, P.; Santangelo, M.; Ferrara, A.; Pelosio, L.; Vallefuoco, D.M.; Caggiano, L.; Imperatore, P. Suboptimal kidney: the experience of a single transplant unit. Transplant Proc. 2004;36(3):488-90.

2. Santangelo, M.; Clemente, M.; Spiezia, S.; Grassia, S.; Di Capua, F.; La Tessa, C.; Iovino, M.G.; Vernillo, A.; Galeotalanza, M. Wound complications after kidney transplantation in nondiabetic patients. Transplant Proc. 2009;41(4):1221-3.

3. Santangelo, M.; Clemente, M.; De Rosa, P.; Zuccaro, M.; Pelosio, L.; Caggiano, L.; La Tessa, C.; Renda, A. The finding of vascular and urinary anomalies in the harvested kidney for transplantation Transplant Proc. 2007;39(6):1797-9.

4. Calogero, A.; Sagnelli, E.; Creta, M.; Angeletti, S.; Peluso, G.; Incollingo, P..; Candida, M.; Minieri, G.; Carlomagno, N.; Dodaro, C.; Ciccozzi, M.; Sagnelli, C. Eradication of HCV infection with the Direct-Acting Antiviral Therapy in renal allograft recipients. BioMed Research International 2019; Article ID 4674560, 8 pages. DOI: 10.1155/2019/4674560. Erratum to "Eradication of HCV Infection with the Direct-Acting Antiviral Therapy in Renal Allograft Recipients","BioMed Research International, 2019, Article ID 8797329, 1 pages. DOI: $10.1155 / 2019 / 8797329$

5. Santangelo, M.; Furian, L.; Kessaris, N.; Hadaya, K.; Kimenai, D.; Bellini, M.I. Renal Transplantation: What Has Changed in Recent Years. Biomed Res Int. 2019;2019:3618104. DOI: $10.1155 / 2019 / 3618104$.

6. Creta, M.; Calogero, A.; Sagnelli, C.; Peluso, G.; Incollingo, P.; Candida, M.; Minieri, G.; Longo, N.; Fusco, F.; Tammaro, V.; Dodaro, C.A.; Mangiapia, F.; Carlomagno, N. Donor and Recipient Outcomes following Robotic-Assisted Laparoscopic Living Donor Nephrectomy: A Systematic Review. Biomed Res Int. 2019;2019:1729138. DOI: $10.1155 / 2019 / 1729138$

7. Pisani, A.; Sabbatini, M.; Imbriaco, M.; Riccio, E.; Rubis. N.; Prinster, A.; Perna, A.; Liuzzi, R.; Spinelli, L.; Santangelo, M.; Remuzzi, G.; Ruggenenti, P.; ALADIN Study Group. 
Long-term Effects of Octreotide on Liver Volume in Patients With Polycystic Kidney and Liver Disease. Clin Gastroenterol Hepatol. 2016;14(7):1022-1030.e4. DOI: 10.1016/j.cgh.2015.12.049.

8. Makiyama, K.; Tanabe, K.; Ishida, H.; Tokumoto, T.; Shimmura, H.; Omoto, K.; Toma, H. Successful renovascular reconstruction for renal allografts with multiple renal arteries . Transplantation. 2003; 75(6):828-32.

9. Vaccarisi, S.; Bonaiuto, E.; Spadafora, N., Garrini, A.; Crocco, V.; Cannistrà, M.; Pellegrino, V.; Cavallari, G.; Nardo, B. Complications and graft survival in kidney transplants with vascular variants: our experience and literature review. Transplant Proc. 2013;45(7):2663-5

10. Benedetti, E.; Troppmann, C.; Gillingham, K.; Sutherland, D.E.; Payne, W.D.; Dunn, D.L.; Matas, A.J.; Najarian, J.S.; Grussner, R.W. Short- and long-term outcomes of kidney transplants with multiple renal arteries. Ann Surg. 1995;221(4):406-14. Review.

11. Santangelo, M.; De Rosa, P.; Spiezia, S.; Spinosa, G.; Grassia, S.; Zuccaro, M.; Renda, A. Healing of surgical incision in kidney transplantation: a single transplant center's experience. Transplant Proc. 2006;38(4):1044-6.

12. Costa, H.C.; Moreira, R.J.; Fukunaga, P.; Fernandes, R.C.; Boni, R.C.; Matos, A.C. Anatomic variations in vascular and collecting systems of kidneys from deceased donors Transplant Proc. 2011;43(1):61-3.

13. Sica, A.; Casale, B.; Dato, M.T.D.; Calogero, A.; Spada, A.; Sagnelli, C.; Santagata, M.; Buonavolontà, P.; Fiorelli, A.; Salzano, A.; Dodaro, C.A.; Martinelli, E.; Saracco, E.: Troiani, T.; Tammaro, D.; Ciardiello, F.; Papa, A. Cancer- and Non-cancer Related Chronic Pain: From the Physiopathological Basics to Management. Open Med (Wars). 2019;14:761766. DOI: $10.1515 / \mathrm{med}-2019-0088$.

14. Vázquez, R.; Garcia, L.; Morales-Buenrostro, L.; Gabilondo, B.; Alberú, J.; Vilatobá, M. Renal grafts with multiple arteries: a relative contraindication for a renal transplant? Transplant Proc. 2010;42(6):2369-71. 
15. Calogero, A.; Sagnelli, C.; Carlomagno, N.; Tammaro, V.; Candida, M.; Vernillo, A.; Peluso, G.; Minieri, G.; Santangelo, M.; Dodaro, C.A. et al. Familial polyposis coli: The management of desmoid tumor bleeding. Open Med (Wars). 2019;14:572-576. DOI: 10.1515/med-2019-0064.

16. Sica, A.; Vitiello, P.; Sorriento, A.; Ronchi, A.; Calogero, A.; Sagnelli, C.; Troiani, T.; Fasano, M.; Dodaro C.A.; Franco, R.; Casale, B.; Santangelo, M.; Ciccozzi, M.;Ciardiello, F.; Argenziano, G.; Moscarella, E. Lymphomatoid papulosis. Minerva Medica in press

17. Criscitiello, C.; Giuliano, M.; Curigliano, G.; De Laurentis, M.; Arpino,G. ; Carlomagno, N.;De Placido, S.; Golshan, M.; Santangelo, M. Surgery of the primary tumor in de novo metastatic breast cancer: To do or not to do? European Journal of Surgical Oncology 2015; 41(10), 4110, 1288-1292.

18. Cagatay, Aydin; Ibrahim, Berber; Gulum, Altaca; Bulent, Yigit; and Izzet Titizl. The outcome of kidney transplants with multiple renal arteries. BMC Surg. 2004; 4 : 4.

19. Oesterwitz, H.; Strobelt, V.; Scholz, D.; Mebel, M. Extracorporeal microsurgical repair of injured multiple donor kidney arteries prior to cadaveric allotransplantation Eur Urol. $1985 ; 11(2): 100-5$

20. Santangelo ML, Criscitiello C, Renda A, Federico S, Curigliano G, Dodaro C, Scotti A, Tammaro V, Calogero A, Riccio E, Pisani A, Carlomagno N. Immunosuppression and Multiple Primary Malignancies in Kidney-Transplanted Patients: A Single-Institute Study. Biomed Res Int. 2015;2015:183523. DOI: 10.1155/2015/183523.

21. Carlomagno, N.; Incollingo, P.; Tammaro, V.; Peluso, G.; Rupealta, N.; Chiacchio, G.; Sandoval Sotelo, M.L.; Minieri, G.; Pisani, A.; Riccio, E.; Sabbatini, M.; Bracale, U.M.; Calogero, A.; Dodaro, C.A.; Santangelo, M. Diagnostic, Predictive, Prognostic, and Therapeutic Molecular Biomarkers in Third Millennium: A Breakthrough in Gastric Cancer. Biomed Res Int. 2017;2017:7869802. DOI: 10.1155/2017/7869802.

22. Ali-El-Dein, B.; Osman, Y.; Shokeir, A.A.; Shehab El-Dein, A.B.; Sheashaa, H.; Ghoneim, M.A. Multiple arteries in live donor renal transplantation: surgical aspects and outcomes, J Urol. 2003;169(6):2013-7. 
23. Sinescu, M.C.; Harza, B.; Serbanescu, B.; Stefan, C.; Baston, M.A.; Manu, V.; Cerempei, D.; Tacu, E.; Kerezsy, C.; Bucsa, L.; Domnisor, D.; Daia, E.; Burchiu, I.; Constantinescu, C. Surcel Impact of vascular anomalies and special anastomotic techniques on early graft function Eur Urol Suppl 2010; 9(6);653

24. Obed, A.; Uihlein, D.C.; Zorger, N.; Farkas, S.; Scherer, M.N.; Krüger, B.; Banas, B.; Krämer, B.K. Severe renal vein stenosis of a kidney transplant with beneficial clinical course after successful percutaneous stenting Am J Transplant. 2008;8(10):2173-6.

25. De Rosa, P.; Santangelo, M.; Scala, A.; Vallefuoco, D.M.; Caggiano, L.; Imbriaco, M.; Spinosa, G. Difficult vascular conditions in kidney transplantation. Transplant Proc. 2006;38(4):1040-3.

26. Mahdavi-Zafarghani, R.; Taghavi, R. Urological complications following renal transplantation: assessment in 500 recipients. Transplant Proc. 2002;34(6):2109-10

27. Sezer, T.O.; Solak, I.; Toz, H.; Kardaslar, B.; Er, A.; Hoscoskun, C. Long-term outcomes of kidney transplants with multiple renal arteries: a retrospective study Transplant Proc. 2012;44(6):1697-9.

28. Zietek, Z.; Sulikowski, T.; Tejchman, K.; Sieńko, J.; Janeczek, M.; Iwan-Zietek, I.; Kedzierska, K.; Rość, D.; Ciechanowski, K.; Ostrowski, M. Lymphocele after kidney transplantation. Transplant Proc. 2007;39(9):2744-7.

29. Sica, A.; Casale, B.; Spada, A.; Di Dato, M.T.; Sagnelli, C.; Calogero, A.; Buonavolontà, P.; Salzano, A.; Martinelli, E.; Saracco, E.; Troiani, T.; Dodaro, C.A.; Tammaro, D.; De Rimini, M.L.; Ciardiello, F.; Papa A. Differential diagnosis: retroperitoneal fibrosis and oncological diseases. Open Med (Wars). In Press

30. Piscitelli P, Santoriello A, Buonaguro FM, Di Maio M, Iolascon G, Gimigliano F, Marinelli A, Distante A, Serravezza G, Sordi E, Cagossi K, Artioli F, Santangelo M, Fucito A, Gimigliano R, Brandi ML, Crespi M, Giordano A; CROM; Human Health Foundation Study Group. Incidence of breast cancer in Italy: mastectomies and quadrantectomies 
performed between 2000 and 2005. J Exp Clin Cancer Res. 2009;28:86. DOI: $10.1186 / 1756-9966-28-86$

31. Başaran, O., Moray, G.; Emiroğlu, R.; Alevli, F.; Haberal, M. Graft and patient outcomes among recipients of renal grafts with multiple arteries. Transplant Proc. 2004;36(1):1024

32. Hwang, J.K.; Kim, S.D.; Park, S.C.; Choi, B.S.; Kim, J.I.; Yang, C.W.; Kim, Y.S.; Moon, I.S. The long-term outcomes of transplantation of kidneys with multiple renal arteries. Transplant Proc. 2010;42(10):4053-7.

33. Takahashi, A.; Hu, S.L.; Bostom, A. Physical activity in kidney transplant recipients: a review. Am J Kidney Dis. 2018;72(3):433-443. DOI:10.1053/j.ajkd.2017.12.005.

34. Zelle, D.M.; Klaassen, G.; van Adrichem, E.; Bakker, S.J.L.; Corpeleijn, E.; Navis, G. Physical inactivity: a risk factor and target for intervention in renal care. Nat Rev Nephrol. 2017;13(3):152-168. DOI:10.1038/nrneph.2016.187.

35. Beddhu, S.; Baird, B.C.; Zitterkoph, J.; Neilson, J.; Greene, T. Physical activity and mortality in chronic kidney disease (NHANES III). Clin $J$ Am Soc Nephrol. 2009;4(12):1901-1906. DOI:10.2215/CJN.01970309.

36. Van den Ham, E.C.; Kooman, J.P.; Schols, A.M. et al. Similarities in skeletal muscle strength and exercise capacity between renal transplant and hemodialysis patients. $A m J$ Transplant. 2005;5(8):1957-1965. DOI:10.1111/j.1600-6143.2005.00944.x

37. Craig, C.L.; Marshall, A.L.; Sjostrom, M. et al. International physical activity questionnaire: 12-country reliability and validity. Med Sci Sports Exerc 2003;35:8:1381-95.

38. Mannocci, A.; Di Thiene, D.; Del Cimmuto, A.; Masala, D.; Boccia, A.; De Vito, E.; La Torre, G. International Physical Activity Questionnaire: validation and assessment in an Italian sample. Ital J Public Health 2010; 7(4):369-76.

39. Firmin, L.C.; Nicholson, M.L. The use of explanted internal iliac artery grafts in renal transplants with multiple arteries. Transplantation. 2010 27;89(6):766-7 
40. Ghazanfar, A.; Tavakoli, A.; Zaki, M.R.; Pararajasingam, R.; Campbell, T.; Parrott, N.R.; Augustine, T.; Riad, H.N. The outcomes of living donor renal transplants with multiple renal arteries: a large cohort study with a mean follow-up period of 10 years Transplant Proc. 2010;42(5):1654-8.

41. Gawish, AE.; Donia, F.; Samhan, M.; Halim, M.A.; Al-Mousawi. M. Outcome of renal allografts with multiple arteries. Transplant Proc. 2007;39(4):1116-7

42. Luke, R.G.; Curtus, J. Biology and treatment of transplant hypertension. In: Laragh JH, Brenner BM, eds. Hypertension: pathophysiology, diagnosis, and management. 2nd ed. New York, NY: Raven, 1995; 2471-2483.

43. Beecroft, J.R.; Rajan, D.K.; Clark, T.W.; Robinette, M.; Stavropoulos, S.W. Transplant renal artery stenosis: outcome after percutaneous intervention. J Vasc Interv Radiol 2004; 15(12):1407-1413.

44. Akbar, S.A.; Jafri, S.Z.; Amendola, M.A.; Madrazo, B.L.; Salem, R.; Bis, K.G. Complications of renal transplantation. RadioGraphics 2005;25(5):1335-1356.

45. Shoskes, D.A.; Hanbury, D.; Cranston, D.; Morris, P.J. Urological complications in 1,000 consecutive renal transplant recipients. J Urol 1995;153(1):18-21.

46. Berger, P.M.; Diamond, J.R. Ureteral obstruction as a complication of renal transplantation: a review. J Nephrol 1998;11(1):20-23.

47. Gerstenkorn, C.; Papalois, V.E.; Thomusch, O.; Maxwell, A.P.; Hakim, N. Surgical management of multiple donor veins in renal transplantation. Int Surg. 2006;91(6):345-7

48. Saidi, R.; Kawai, T.; Kennealey, P.; Tsouflas, G.; Elias, N.; Hertl, M.; Cosimi, A.B.; Ko, D.S. Living donor kidney transplantation with multiple arteries: recent increase in modern era of laparoscopic donor nephrectomy. Arch Surg. 2009;144(5):472-5

49. Keller, J.E.; Dolce, C.J.; Griffin, D.; Heniford, B.T.; Kercher, K.W. Maximizing the donor pool: use of right kidneys and kidneys with multiple arteries for live donor transplantation. Surg Endosc. 2009;23(10):2327-31 
50. Kacar, S., Gurkan, A.; Akman, F.; Varýlsuha, C.; Karaca, C.; Karaoglan, M. Multiple renal arteries in laparoscopic donor nephrectomy. Ann Transplant. 2005;10(2):34-7

51. Dodd, G.D.; Tublin, M.E.; Shah, A. et al. Imaging of vascular complications associated with renal transplantation. AJR Am J Roentgenol 1991; 157:449- 459

52. Lubrano, R.; Tancredi, G.; Bellelli, E.; Gentile, I.; Scateni, S.; Masciangelo, R. et al. Influence of physical activity on cardiorespiratory fitness in children after renal transplantation. Nephrol Dial Transplant 2012;27:1677-81.

53. Zelle, D.M.; Corpeleijn, E.; Stolk, R.P. et al. Low physical activity and risk of cardiovascular and all-cause mortality in renal transplant recipients. Clin J Am Soc Nephrol 2011;6(4):898-905.

54. Rambod, M.; Shabani, M.; Shokrpour, N.; Rafii, F.; Mohammadalliha, J. Quality of life of hemodialysis and renal transplantation patients. Health Care Manag (Frederick) 2011;30(1): 23-8. DOI: 10.1097/HCM.0b013e3182078ab6

55. Buzgova, R.; Smotkova, S. Comparing of life in dialysis patients and patients after kidney transplantation: a questionnaire survey. Cas Lek Cesk 2013;152(5):233-9.

56. Johansen, K.L. Exercise and chronic kidney disease: current recommendations. Sports Med 2005;35(6):485-99.

57. Painter, P.; Carlson, L.; Carey, S.; Paul, S.M.; Myll, J. Physical functioning and healthrelated quality-of-life changes with exercise training in hemodialysis patients. Am $J$ Kidney Dis 2000;35(3): 482-92.

58. Van den Ham, E.C.; Kooman, J.P.; Schols, A.M. et al. The functional, metabolic and anabolic responses to exercise training in renal transplant and hemodialysis. Transplantation 2007;83(8):1059-68.

59. Levendoglu, F.; Altintepe, L.; Okudan, N. et al. A twelve week exercise program improves the psychological status, quality of life and work capacity in hemodialysis patients. $J$ Nephrol 2004;17(6): 826-32. 
60. Mazzoni, D.; Cicognani, E.; Mosconi, G. et al. Sport activity and health-related quality of life after kidney transplantation. Transplant Proc 2014;46(7):2231-4

61. Ferrarese, A.; Pozzi, G.; Borghi, F.; Pellegrino, L.; Di Lorenzo, P.; Amato, B.; Santangelo, M.; Niola, M.; Martino, V.; Capasso, E. Informed consent in robotic surgery: quality of information and patient perception. Open Med (Wars). 2016;11(1):279-285. 
Table 1. Clinical Characteristics of patients who underwent kidney transplantation: MRA versus SRA groups.

\begin{tabular}{|c|c|c|}
\hline Characteristic & Group 1 (MRA) & Group 2 (SRA) \\
\hline Number of recipients & 34 & 34 \\
\hline Recipient age, years $(\mathrm{M} \pm \mathrm{SD})$ & $55 \pm 8$ & $55 \pm 7$ \\
\hline Donor age, years $(\mathrm{M} \pm \mathrm{SD})$ & $41 \pm 14$ & $43 \pm 13$ \\
\hline \multicolumn{3}{|c|}{ Postoperative Creatinine clearance, $\mathrm{mL} / \mathrm{min}(\mathrm{M} \pm \mathrm{SD})$} \\
\hline 1 years & $2.2 \pm 0.6$ & $2.5 \pm 0.8$ \\
\hline 3 years & $2.1 \pm 0.3$ & $2.2 \pm 0.7$ \\
\hline 5 years & $2.0 \pm 0.2$ & $1.8 \pm 0.4$ \\
\hline \multicolumn{3}{|c|}{ Mean Systolic blood Pressure, $\mathrm{MmHg}(\mathrm{M} \pm \mathrm{SD})$} \\
\hline 1 years & $130 \pm 10$ & $125 \pm 9$ \\
\hline 3 years & $132 \pm 7$ & $112 \pm 8$ \\
\hline 5 years & $120 \pm 6$ & $110 \pm 9$ \\
\hline
\end{tabular}

MRA: multiple renal artery group; SRA: standard renal artery group. 
Table 2. Postoperative Complications after MRA versus SRA Transplantation

\begin{tabular}{|l|l|c|}
\hline Complication & Group 1 (MRA) & Group 2 (SRA) \\
\hline Number of recipients & 34 & 34 \\
\hline Vascular, N (\%): & & 0 \\
\hline Renal Artery thrombosis & $1(2.9 \%)$ & $1(1.9 \%)$ \\
\hline Lrologic, N (\%): & $1(2.9 \%)$ & $2(5.8 \%)$ \\
\hline Lymphocele & 0 & $4(11.8 \%)$ \\
\hline Total & $4(11.8 \%)$ & $20.6 \%$ \\
\hline
\end{tabular}

MRA: multiple renal artery group; SRA: standard renal artery group. 
Figure 1.

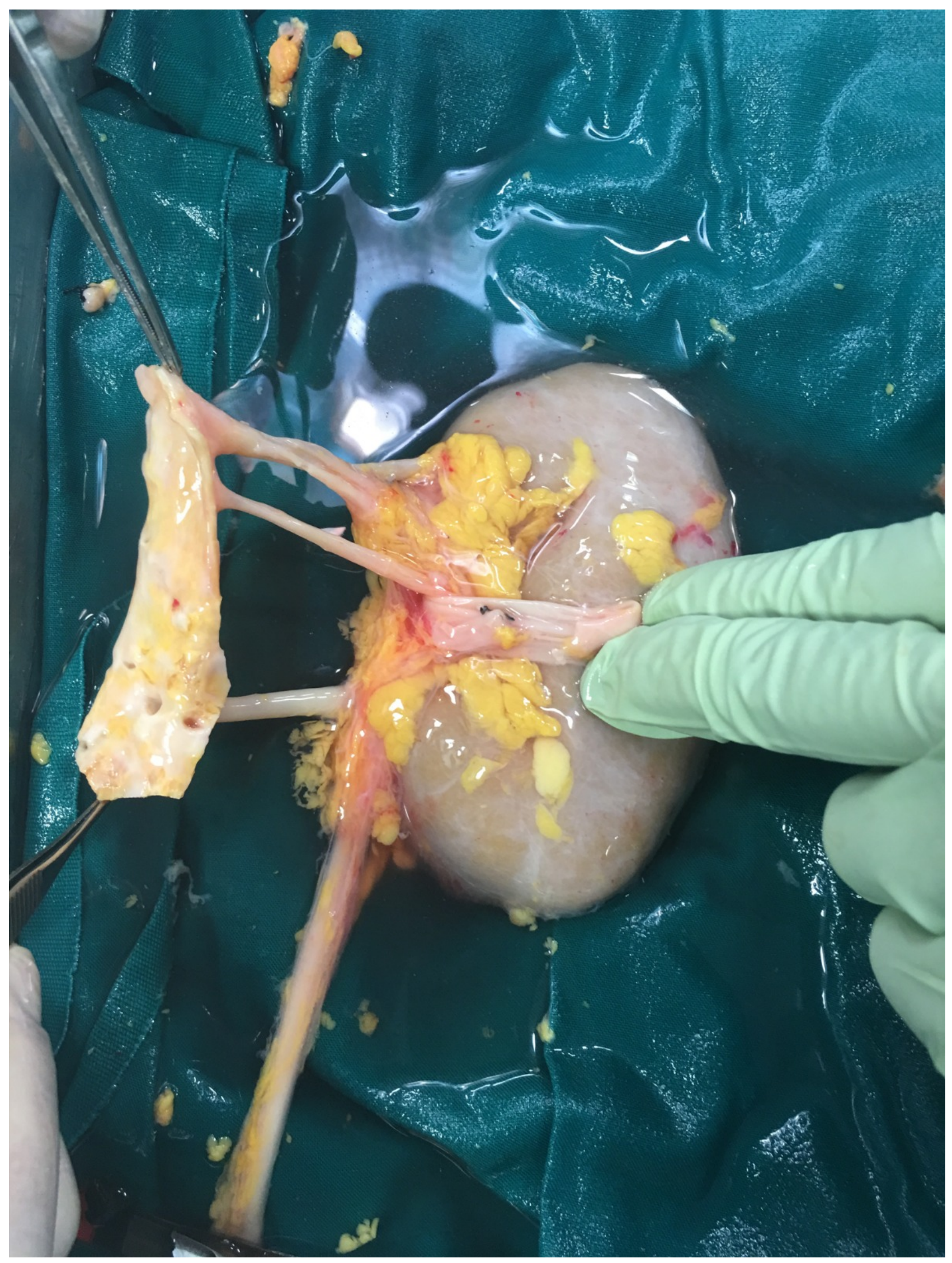

